\section{Ultrasonographic salivary gland evaluation in systemic sclerosis: is sicca syndrome secondary to an authentic overlap syndrome or another specific fibrotic manifestation of the disease?}

We read with great interest the results of Couderc and colleagues concerning ultrasonographic (US) involvement of major salivary glands (SGs) in systemic sclerosis (SSc). ${ }^{1}$ We fully agree with their comment concerning the high prevalence of sicca syndrome in SSc and its underestimated impact on quality of life. US evaluation of major SGs is a non-irradiating, easy-to-use and largely available tool. Its diagnostic performances have been properly evaluated in primary Sjögren syndrome $(\mathrm{SS})^{2}$ and can be extended to secondary SS. In their study, Couderc and colleagues highlight the high prevalence of overlap syndrome SSc/primary SS according to US evaluation. Nonetheless, this overlap syndrome may not be the only mechanism underlying sicca syndrome in SSc. As initially suggested by Couderc and colleagues, a specific SSc-associated fibrosis of major SGs could also explain sicca syndrome in SSc. ${ }^{13}$ This hypothesis is all the more relevant as such glandular fibrosis has already been described in minor SGs of SSc patients. ${ }^{3}$ Although the US Cornec's score used by Couderc and colleagues has good diagnostic performances for the diagnosis of primary SS, this score may have some limits for the detection of fibrosis of major SG in SSc. ${ }^{4}$ Indeed, hyperechoic bands, a fibrotic feature, are not included in US Cornec's score as a specific and isolated item but are only considered as a manifestation of a pseudocystic degeneration of the gland (grade 3 and 4), which is supposed to be specific of primary SS. Hyperechoic bands have on the contrary been fully integrated in the recent scoring system of Outcome Measures in Rheumatology (OMERACT) for major SG US evaluation ${ }^{5}$ (figure 1). Therefore, US assessment according to Cornec's score may underestimate the prevalence of SSc-associated fibrosis of major SGs and may more specifically select patients with overlap syndrome with primary SS. This hypothesis is concordant with Avouac's results on minor SG biopsy, showing that overlap syndrome with primary SS was only detect in $14 \%$ of SSc patients whereas the first cause of sicca syndrome in this study was SSc-associated glandular fibrosis, both in diffuse and limited cutaneous SSc, and independently from SS-associated lymphocytic sialadenitis. ${ }^{3}$

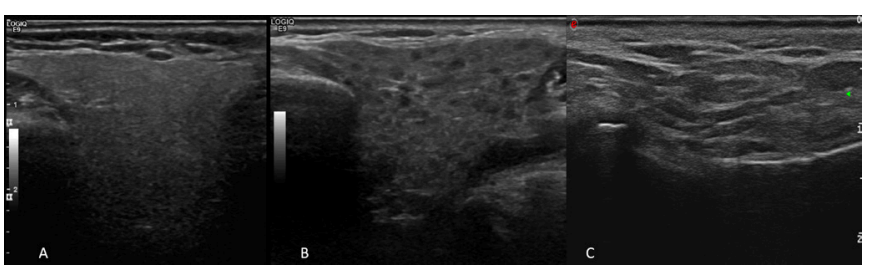

Figure 1 US axial view of a normal $(A)$ and pathologic $(B-C)$ parotid gland. (B) shows pathological glandular parenchyma with multiple pseudo-cystichypoechoic areas and some fibrotic hyperechoic bands. This gland would be classified as grade 3 of Cornec's score and grade 2 according to OMERACT classification.(C) shows a pathological glandular parenchyma with hyperechoic bands that develop into fibrotic tissue indistinguishable from the adjacent soft tissues and with only few pseudo-cystic hypoechoic areas. This gland would be difficult to classify according to Cornec's score (considered as grade 1 or 2) and would on the contrary easily reach grade 3 according to the recent OMERACT score.
Therefore, a full exploration of sicca syndrome and its correlation with US features of major SGs in SSc may require a comparison of the histological findings from minor SGs with US results from major SGs. This comparison of US features with histological findings may help to precise the pathogenesis underlying major SG involvement in SSc. Acoustic radiation force impulse-elastometry of these major glands may also help to clarify this issue and to more precisely detect major gland fibrosis in SSc, although the reproducibility of this technic is still to be confirmed. Moreover, as vascular involvement is a hallmark of the pathogenesis of SSc, Doppler waveform analysis of the transverse facial artery may reveal narrowing, occlusions or altered resistance index, offering new insights in the pathogenesis of major SG involvement in SSc. An OMERACT US study of SG vascularisation is ongoing to clarify this issue in primary SS and its relevance in SSc still needs to be confirmed.

Organ involvement is complex and multifactorial in SSc, and like heart or lung involvement, major SGs impairment may be the result of simultaneous and combined pathogenic pathways, beyond primary SS overlap syndrome. If we acknowledge that Couderc and colleagues' study lays the foundations for US evaluation of major SG involvement in SSc, ${ }^{1}$ we believe that a global US assessment combining vascular, fibrotic and inflammatory features of major SGs in comparison with biopsies of minor SGs is therefore still needed to better understand sicca syndrome in SSc. We are currently conducting a multicentre cross-sectional study exploring this issue and hope that this global US approach may provide new insights into this frequent but neglected manifestation of this complex autoimmune disorder. ${ }^{6}$

Guillaume Coiffier, ${ }^{\circ 1}$ Sandrine Jousse-Joulin, ${ }^{\circ 2}$ Divi Cornec, ${ }^{2}$ Ronan Garlantézec, ${ }^{3}$ Aurore Bleuzen, ${ }^{4}$ Elisabeth Diot, ${ }^{5}$ Patrick Jego, ${ }^{6}$ Alice Ballerie, ${ }^{6}$ Alain Lescoat ${ }^{\circ 6}$

${ }^{1}$ Rhumatology department and U1241, CHU Rennes, Univ Rennes, Inserm, Rennes, France

${ }^{2}$ Rheumatology department and U1227, Lymphocytes B et Autoimminité, Univ Brest, Inserm, Brest, France

${ }^{3}$ Public Health and Epidemiology department, Univ Rennes, CHU Rennes, Inserm, EHESP, Irset (Institut de recherche en santé, environnement et travail)-UMR_S1085, F-35000 Rennes, France

${ }^{4}$ Radiology department, CHRU Tours, Tours, France

${ }^{5}$ Internal Medicine, CHU Tours, university of Tours, Tours, France

${ }^{6}$ Internal Medicine and Clinical Immunology, Univ Rennes, CHU Rennes, Inserm, EHESP, Irset (Institut de recherche en santé, environnement et travail)-UMR_S1085, F-35000 Rennes, France

Correspondence to Dr Alain Lescoat, Internal Medicine, CHU South Hospital, Rennes 35203, France; alain.lescoat@chu-rennes.fr

Acknowledgements The authors thank the 'CORECT' (comite de la recherche clinique et translationnelle de Rennes), Mme Agnès Gazzola, Mr Romain Muraz and Mme Mathilde Ouvrard from the « Direction de la Recherche et de I'Innovation du CHU de Rennes » (DRI) for their technical and administrative support.

Contributors GC, SJ-J, DC, RG, AB, ED, PJ, $A B$ and $A L$ wrote the first draft of the manuscript and added substantial modifications to the final version.

Funding The authors have not declared a specific grant for this research from any funding agency in the public, commercial or not-for-profit sectors.

Competing interests None declared.

Patient consent for publication Not required.

Provenance and peer review Not commissioned; internally peer reviewed. (C) Author(s) (or their employer(s)) 2019. No commercial re-use. See rights and permissions. Published by BMJ.

\section{Check for updates}

To cite Coiffier G, Jousse-Joulin S, Cornec D, et al. Ann Rheum Dis Epub ahead of print: [please include Day Month Year]. doi:10.1136/annrheumdis-2019-215972 
Correspondence

Received 1 July 2019

Accepted 5 July 2019

Ann Rheum Dis 2019;0:1-2. doi:10.1136/annrheumdis-2019-215972

\section{REFERENCES}

1 Couderc M, Tournadre A, Mathieu S, et al. Do the salivary glands of patients with systemic sclerosis show ultrasonographic modifications suggestive of Sjögren's syndrome? Ann Rheum Dis 2019. doi:10.1136/annrheumdis-2019-215777. [Epub ahead of print: 12 Jun 2019].

2 Jousse-Joulin S, Nowak E, Cornec D, et al. Salivary gland ultrasound abnormalities in primary Sjögren's syndrome: consensual US-SG core items definition and reliability. RMD Open 2017;3:e000364
3 Avouac J, Sordet C, Depinay C, et al. Systemic sclerosis-associated Sjögren's syndrome and relationship to the limited cutaneous subtype: results of a prospective study of sicca syndrome in 133 consecutive patients. Arthritis Rheum 2006;54:2243-9.

4 Cornec D, Jousse-Joulin S, Pers J-0, et al. Contribution of salivary gland ultrasonography to the diagnosis of Sjögren's syndrome: toward new diagnostic criteria? Arthritis Rheum 2013:65:216-25.

5 Jousse-Joulin S, D'Agostino MA, Nicolas C, et al. Video clip assessment of a salivary gland ultrasound scoring system in Sjögren's syndrome using consensual definitions: an OMERACT ultrasound Working group reliability exercise. Ann Rheum Dis 2019;78:967-73.

6 ClinicalTrials.gov identifier (NCT number): NCT04001556. 